\title{
Optimization and Validation of Microalgal Growth Condition by Response Surface Methodology (RSM)
}

\author{
Vivek P. Pankaj ${ }^{1}$ and Mamta Awasthi ${ }^{2}$ \\ ${ }^{1}$ Senior research scholar and ${ }^{2}$ Assistant professor \\ Centre for Energy and Environmental Engineering, \\ National Institute of Technology-Hamirpur (H.P)-177005, India \\ vppbiotech@gmail.com
}

\begin{abstract}
Microalgae biofuels may provide a viable alternative to fossil fuels which has received considerable interest now a days, but if microalgae biofuel production is to be economically viable and sustainable to mitigate the energy crises. Although there is much excitement about the potential of microalgae biofuels, much work is still required in the field. So further optimization of growth conditions are needed to make a different sources which provide costeffective and sustainable means of native microalgae growth for biofuel production. This paper shows that the optimization of environmental condition i.e. Temperature, $p H$ and light period for the growth of native microalgae sp. for biofuel production and validation of experimental model by using response surface methodology (RSM).
\end{abstract}

Keywords: Microalgae; Lipid extraction; Response surface methodology (RSM)

\section{Introduction}

Microalgae are a diverse group of single-celled organisms that have the potential to offer a variety of solutions for our liquid transportation fuel requirements through a number of avenues. Microalgae species grow in a wide range of aquatic environments, from freshwater through saturated saline. Microalgae are one of the most important bioresources that are currently receiving a lot of attention due to a multiplicity of reasons. The world is faced with energy challenges in the near future and it is reported that fossil fuel reserves will be depleted in half a century [1]. This will be an unprecedented vicissitude that will impact negatively on all anthropogenic activities most importantly agriculture, industry and commerce. With this in mind, it is crucial to explore renewable and cost-effective sources of energy for the future sustainability. It has been estimated that biomass could provide about $25 \%$ of global energy requirements and can also be a source of valuable chemicals, pharmaceuticals and food additives [2]. All algae have the capacity to produce energy-rich oils, and a number of microalgae species have been found to naturally accumulate high oil levels in total dry biomass.

This paper shows that the optimization of environmental condition i.e., Temperature, $\mathrm{pH}$ and light period for the growth of native microalgae $\mathrm{sp}$. for biofuel production and validation of experimental model by using response surface methodology (RSM). 


\section{Materials and Methods}

\subsection{Growth Parameters of Microalgae}

Microalgae samples like; 1. CEE-1: Chlorophyceae sp; 2. CEE-2: Bracteacoccus sp; 3. CEE-3: Nannochloropsis sp; 4. CEE-4: Oedogonium sp; 5. CEE-5: Desmodesmus sp; 6. CEE-6: Oscillatoria $s p$; 7. CEE-7: Chlorella $s p$; 8. CEE-8: Microcystis sp; 9. CEE-9: Schroederia setigera; 10.CEE-10: Selenastrum sp; 11. CEE-11: Urospora sp, were taken from Centre for Energy and Environment, NIT-Hamirpur-India. These samples were grown in several environmental conditions (Optimized $\mathrm{pH}$, temperature, light period and combined all optimized condition) using Bold's basal medium and CHU\#10 medium, at 21 days of time interval. These three parameters of environmental condition like $\mathrm{pH}$, temperature and light period were taken with different ranges which has to be optimized in respect of microalgae samples growth like, $\mathrm{pH}$ was used 5 to 11 , temperature in range of $10^{\circ} \mathrm{C}, 20^{\circ} \mathrm{C}, 25^{\circ} \mathrm{C}, 30^{\circ} \mathrm{C}$, $40^{\circ} \mathrm{C}$ and light period in range 6 to $24 \mathrm{LP}$ (light period) with having $6 \mathrm{~W} / \mathrm{m}^{2}$ light intensity and growth was measured by OD (optical density) which is taken by UV-spectrophotometer (Agilent cary-100) at $680 \mathrm{~nm}$. The initial dry weight was used for growing all microalgae $s p$. $0.0157,0.2657,0.01275,0.01605,0.02596,0.01944,0.0163,0.01623,0.01808,0.01759$, and 0.01625 (in $\mathrm{gm} / 10 \mathrm{ml}$ ) respectively and percentage of total lipid extraction was done by Bligh \& Dyer method [3].

\subsection{Design of Experiments and Validation of Experimental Model by using RSM}

Response surface methodology (RSM) is a widely accepted statistical technique used to design the experiments. Mainly, RSM follows three major steps consisting of carrying out statistically designed experiments, evaluating the coefficients in a mathematical model with prediction of response and examining the adequacy of the model. It is very useful for modelling and predicting the response of interest affected by a number of input variables with the aim of optimizing the responses. RSM can find the optimal set of experimental parameters that produce a maximum or minimum value of response, and can represent the direct and interactive effects of process parameters through two- and three-dimensional plots. The most popular response surface design (central composite design) is used to formulate the present design of experiments in this study.

\subsubsection{Test for Significance on Individual Model Coefficients}

This test forms the basis for model optimisation by adding or deleting coefficients through backward elimination, forward addition or stepwise elimination/addition/exchange. It involves the determination of the P-value or probability value, usually relating the risk of falsely rejecting a given hypothesis. For example, a "Prob. > F" value on an F-test tells the proportion of time one would expect to get the stated F-value if no factor effects are significant. The "Prob. > F" value determined can be compared with the desired probability or $\alpha$-level. In general, the lowest order polynomial would be chosen to adequately describe the system and this system will validates the experimental model by statistical analysis using ANOVA (Analysis of variance) for Response Surface Reduced Quadratic Model. Additionally, checks need to be made in order to determine whether the model actually describes the experimental data [4]. The checks performed here include determining the various coefficient of determination, R2. These R2 coefficients have values between 0 and 1 . In addition to the above, the adequacy of the model is also investigated by the examination of residuals [5]. The residuals, which are the difference between the respective, observe 
responses and the predicted responses are examined using the normal probability plots of the residuals and the plots of the residuals versus the predicted response. If the model is adequate, the points on the normal probability plots of the residuals should form a straight line. On the other hand the plots of the residuals versus the predicted response should be structure less, that is, they should contain no obvious patterns.

\subsubsection{Validation of the Developed RSM Models with Analytical Data}

In order to validate the developed RSM models, experimental (actual) results obtained of microalgae growth of all samples were compared with predicted results of RSM as shown in Figure 4. From the validation tests, it is obtained that the predicted error is very small between the actual and predicted values, which shows a good agreement between the developed RSM models and experimental model.

\section{Result and Discussion}

\subsection{Optimization of microalgae sp Growth}

All experiments were designed and analysed by RSM which is a statistical technique used to design of experiments called design of experiment 7.0 software. Around 22 sets of experiments designed for optimizing the growth of all microalgae $s p$ in respect of biomass at incubation period of 21 days. All experiments were done in triplet form. The result of predicted values were almost similar in comparison of actual values of experimental results of all microalgae samples. This model gave an optimized value of all environmental parameters i.e. temperature, $\mathrm{pH}$ and light period (LP) in respect of its growth or biomass individually. The result of all optimized environmental condition of all microalgae were shown in Figure 1, which shows the variation in growth in different environmental condition.

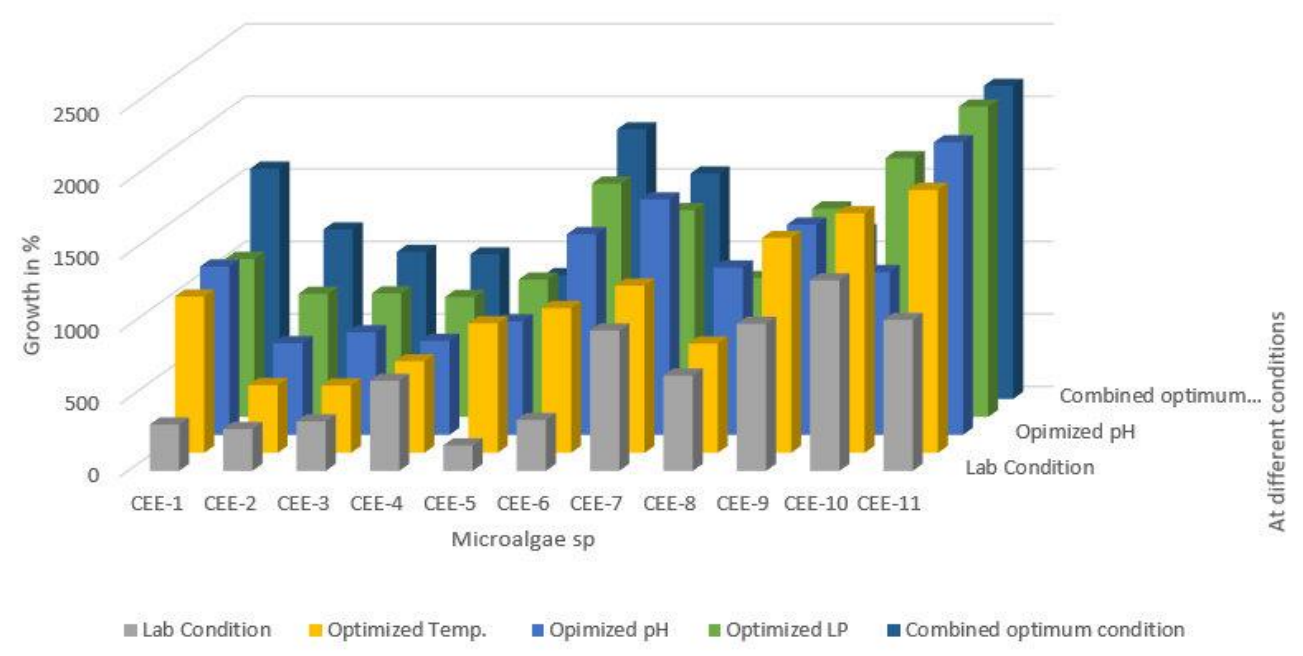

Figure 1. Growth of all Microalgae sp in Different Environmental Condition

The concentration of total lipid extraction of all microalgae in different environment condition as shown in Figure 2, which shows that the variation in lipid content in all microalgae samples. 


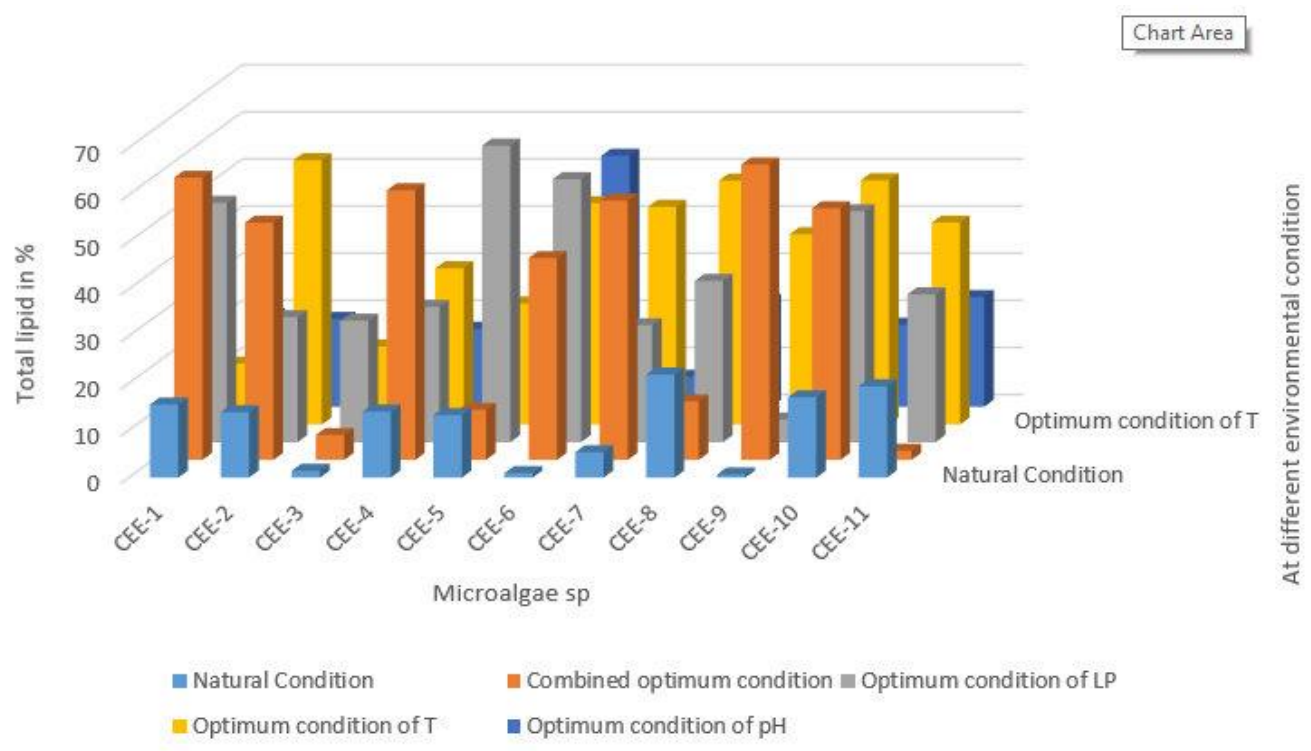

Figure 2. \% of Total Lipid Concentration in Different Environmental Condition of all Microalgae

\subsection{ANOVA (Analysis of Variance) for Response Surface Reduced Quadratic Model}

The analysis of variance (ANOVA) for optimizing growth of microalgae was used in order to validate the model, as given in Table 1. F-value of model should be greater than the tabulated value of the F-distribution for a certain number of degrees of freedom at a level of significance. The final equation final equation in terms of coded factors, $R^{2}$, adjusted $R^{2}, F-$ value and P-value (Prob $>\mathrm{F}$ ) of all microalgae samples was shown in Table 1 . The values of "Prob > F" less than 0.0500 indicate model terms are significant in case of all microalgae samples. In this case A, B, C were significant model terms, values greater than 0.1000 indicate the model terms are not significant, which is not found in this experiments.

Table 1. ANOVA (Analysis of Variance) for Response Surface Reduced Quadratic Model

\begin{tabular}{|c|c|c|c|c|c|}
\hline $\begin{array}{l}\text { Biomass/ } \\
\text { Growth }\end{array}$ & $\begin{array}{l}\text { Final equation Final } \\
\text { Equation in Terms of } \\
\text { Coded Factors: }\end{array}$ & $\mathbf{R}^{2}$ & $\begin{array}{l}\text { Adjusted } \\
\mathbf{R}^{2}\end{array}$ & F-value & $\begin{array}{l}\text { P-value } \\
(\text { Prob > F })\end{array}$ \\
\hline CEE-1 & $\begin{array}{l}\text { Microalgae } \\
\text { growth=+1101.20+51.60* } \\
\text { A-197.71* B-104.28*C- } \\
939.63 * \mathrm{~A}^{\wedge} 2-850.09^{*} \mathrm{~B}^{\wedge} 2- \\
685.00^{*} \mathrm{C}^{\wedge} 2\end{array}$ & 0.9728 & 0.9602 & 77.45 & $<0.0001$ \\
\hline CEE-2 & $\begin{array}{l}\text { Microalgae growth }=+615.82- \\
57.30 * \mathrm{~A}+349.03 * \mathrm{~B}- \\
397.08^{*} \mathrm{~A}^{\wedge} 2-125.94^{*} \mathrm{~B}^{\wedge} 2\end{array}$ & 0.9528 & 0.9402 & 75.64 & $<0.0001$ \\
\hline CEE-3 & $\begin{array}{l}\text { Microalgae growth } \\
=+663.39+10.95^{*} \mathrm{~A} \\
+361.63^{*} \mathrm{~B}+246.53^{*} \mathrm{C}- \\
391.49^{*} \mathrm{~A}^{\wedge} 2-136.91 * \mathrm{~B}^{\wedge} 2- \\
124.72^{*} \mathrm{C}^{\wedge} 2\end{array}$ & 0.9484 & 0.9246 & 39.82 & $<0.0001$ \\
\hline
\end{tabular}




\begin{tabular}{|c|c|c|c|c|c|}
\hline CEE-4 & $\begin{array}{l}\text { Microalgae growth } \\
=+687.57-31.05^{*} \mathrm{~A} \\
+136.70^{*} \mathrm{~B}-61.87 * \mathrm{C}- \\
487.36^{*} \mathrm{~A}^{\wedge} 2-518.50^{*} \mathrm{~B}^{\wedge} 2- \\
79.33^{*} \mathrm{C}^{\wedge} 2\end{array}$ & 0.9611 & 0.9432 & 53.55 & $<0.0001$ \\
\hline CEE-5 & $\begin{array}{l}\text { Microalgae growth } \\
=+637.45+409.05^{*} \mathrm{~B}\end{array}$ & 0.6240 & 0.6031 & 29.87 & $<0.0001$ \\
\hline CEE-6 & $\begin{array}{l}\text { Microalgae growth } \\
=+1229.34+66.90 * \mathrm{~A} \\
+617.79 * \mathrm{~B}+393.83 * \mathrm{C}- \\
786.20^{*} \mathrm{~A}^{\wedge} 2 \\
-252.21 * \mathrm{~B}^{\wedge} 2\end{array}$ & 0.9576 & 0.9425 & 63.27 & $<0.0001$ \\
\hline CEE-7 & $\begin{array}{l}\text { Microalgae growth } \\
=+853.46+277.80 * \mathrm{~A} \\
-642.80 * \mathrm{~B}-550.84 * \mathrm{C}- \\
753.63^{*} \mathrm{~A}^{\wedge} 2-195.85^{*} \mathrm{~B}^{\wedge} 2\end{array}$ & 0.9519 & 0.9348 & 55.46 & $<0.0001$ \\
\hline CEE-8 & $\begin{array}{l}\text { Microalgae growth } \\
=+498.43+9.90 * \mathrm{~A} \\
-408.84 * \mathrm{~B}-457.59 * \mathrm{C}- \\
606.98 * \mathrm{~A}^{\wedge} 2\end{array}$ & 0.9525 & 0.9398 & 75.17 & $<0.0001$ \\
\hline CEE-9 & $\begin{array}{l}\text { Microalgae } \\
\text { growth=+1369.55-232.95*A } \\
-161.53 * \mathrm{~B}-171.58^{*} \mathrm{C}- \\
1033.37^{*} \mathrm{~A}^{\wedge} 2-1283.83 * \mathrm{~B}^{\wedge} 2- \\
292.25^{*} \mathrm{C}^{\wedge} 2\end{array}$ & 0.9616 & 0.9438 & 54.21 & $<0.0001$ \\
\hline CEE-10 & $\begin{array}{l}\text { Microalgae growth } \\
=+1560.41-20.25^{*} \mathrm{~A} \\
+513.63 * \mathrm{~B}-201.31^{*} \mathrm{C}- \\
1179.76^{*} \mathrm{~A}^{\wedge} 2-880.66^{*} \mathrm{~B}^{\wedge} 2- \\
734.20^{*} \mathrm{C}^{\wedge} 2\end{array}$ & 0.9502 & 0.9272 & 41.31 & $<0.0001$ \\
\hline CEE-11 & $\begin{array}{l}\text { Microalgae } \\
\text { growth=+2014.79-198.00 } \\
\text { *A-50.76*B- } \\
1568.13 * \mathrm{~A}^{\wedge} 2-883.45 * \mathrm{~B}^{\wedge} 2\end{array}$ & 0.9831 & 0.9786 & 217.78 & $<0.0001$ \\
\hline
\end{tabular}

Where; $\mathrm{A}=$ Temperature, $\mathrm{B}=$ Light period and $\mathrm{C}=\mathrm{pH}$

\subsection{Regression Diagnostic was Carried Out in Order to Check the Model's Adequacy:}

3.3.1 Normal Probability Plot of residuals is useful to check the assumption that the errors are normally distributed. A check on the plot in Figure 3 reveals that the residuals follow a straight line and so the errors seem to be normally distributed. We clarify that in this case too many parameters are estimated to justify this as a test. We can consider it as a descriptive approach. The growth pattern of microalgae samples showed in 3D structure which reveals all effects of all environmental parameters clearly and normal probability plot of residuals and the Plot of predicted vs. actual values were shown in Figure 3. 

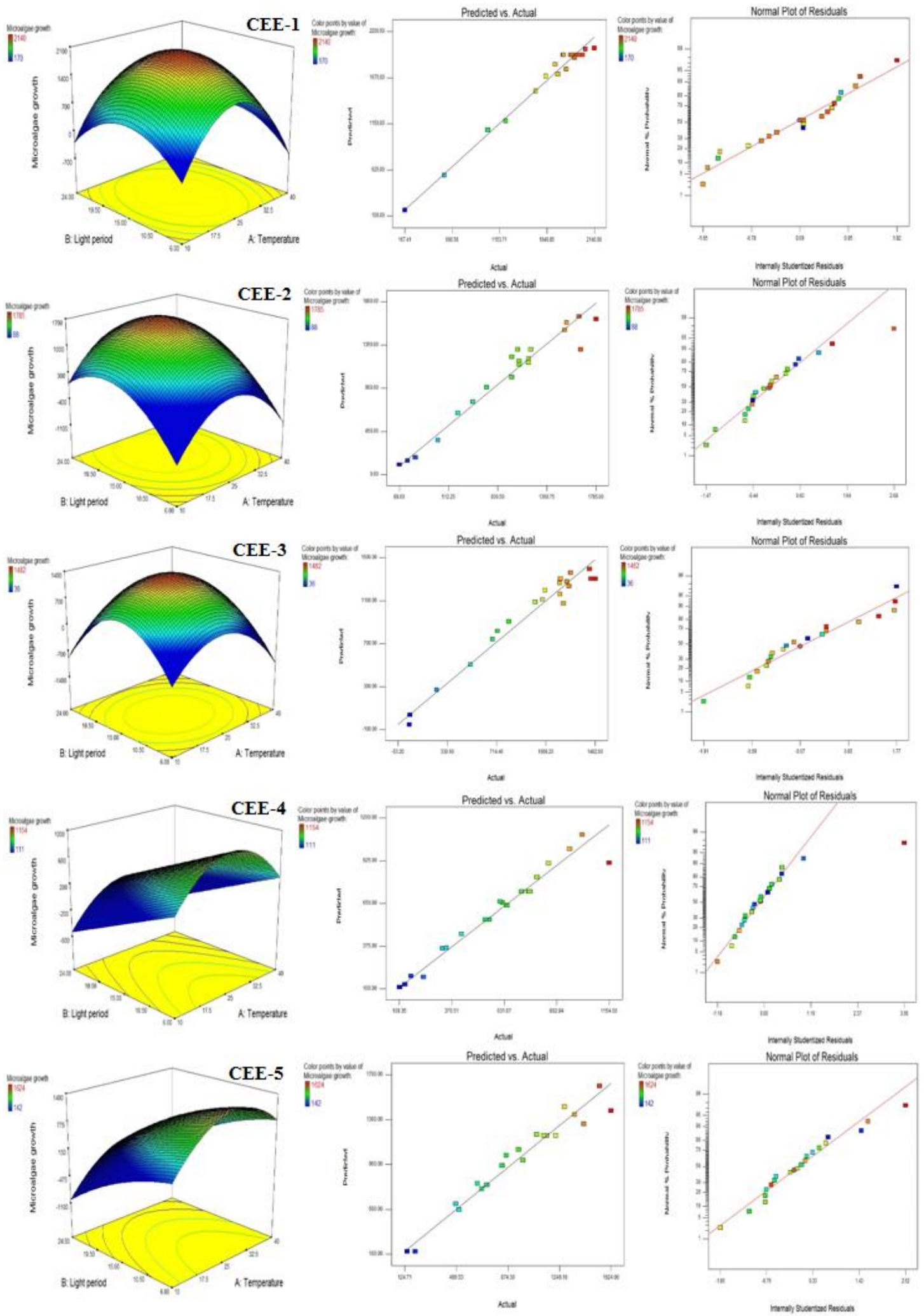

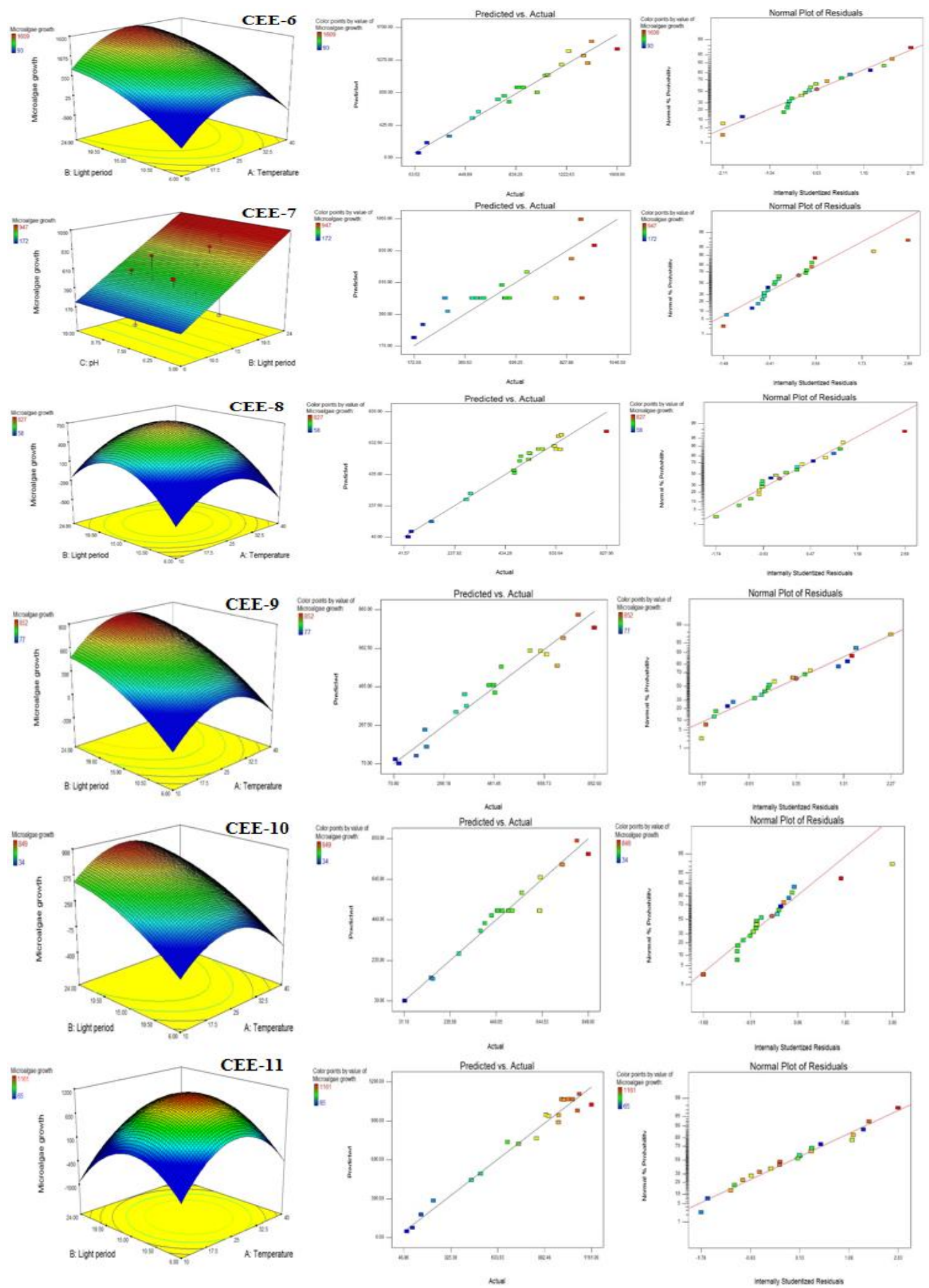

Figure 3. 3D Surface Graphs, Normal Probability Plot of Residuals and the Plot of Predicted vs. Actual Values of all Samples of Microalgae from CEE-1 to CEE- 


\section{Conclusion}

Eleven species of microalgae were studied in respect of their growth or biomass and extraction of total lipid content, which have been optimized in different environmental condition and this design of experiment validated by using RSM. The validity and adequacy of the predicted models was successfully verified by significant F-values.

\section{Acknowledgements}

First and second authors thanks to Centre for Energy and Environmental Engineering, National Institute of Technology, Hamirpur, H.P, India, for their support in this study.

\section{References}

[1] Y. Chisti, "Biodiesel from microalgae", Biotechnol Adv., vol. 25, (2007), pp. 249-306.

[2] C. Briens, J. Piskorz and F. Berruti, "Biomass valorization for fuel and chemicals production: A review", Int J Chem React Eng., vol. 6, (2008), pp. 1-49.

[3] E. G. Bligh and W. J. Dyer, "A rapid method of total lipid extraction and purification", Can J Biochem Physiol., vol. 37, (1959), pp. 911-917.

[4] T. Akar and S. Tunali, "Biosorption performance of Botrytis cinerea fungal by-products for removal of $\mathrm{Cd}(\mathrm{II})$ and $\mathrm{Cu}(\mathrm{II})$ ions from aqueous solutions”, Miner Eng., vol. 18, (2005), pp. 1099-109.

[5] Culp SJ, Beland FA. Malachite green: a toxicological review. Int J Toxicol., vol. 15, (1996), pp. 219-38.

\section{Authors}

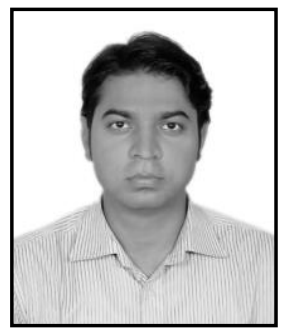

Vivek Prakash Pankaj is currently working as $\mathrm{PhD}$ research Scholar at Centre for Energy and Environmental Engineering, National Institute of Technology- Hamirpur (H.P)-177005 and his research interest is algal biofuel and Waste water treatment and waste management etc.

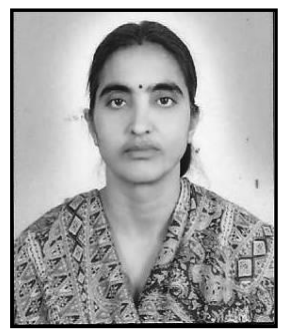

Dr. Mamta Awasthi, is currently working as an Assistant Professor at Centre for Energy and Environmental Engineering, National Institute of Technology- Hamirpur (H.P)-177005. She has done PhD, Post Doc., Msc in Botany and having various publication in Botany as well as Biofuel, algae etc. 